\title{
Spelling errors of EFL students
}

\author{
An insight into curriculum development
}

[Sheikha Ali Salim Al-Breiki]

\begin{abstract}
The purpose of this study was to explore the types of the spelling errors students of grade ten make and to find out whether there were any significant differences between males and females with respect to the types of the spelling errors made. The sample of the study included 90 grade ten students from four different schools in Oman. The researcher collected the research data via using a test that consisted of two questions: a dictation question of 70 words with a contextualizing sentence and a free writing task. The misspellings were classified into nine different types. The findings revealed that the most common spelling errors among Omani grade ten students were vowel substitution, then came vowel omission in the second place and consonant substitution in the third place. Male students omitted more vowels than female students while females made more true word errors than their male counterparts. In light of the findings, the study presents some recommendations for curriculum development and suggestions for further studies.
\end{abstract}

Keywords: types of spelling errors, errors, ESL/EFL, error analysis

\section{Introduction}

ESL/EFL learners face difficulties with various aspects of the language including spelling. Spelling is considered as the starting point of the written language as indicated by Mahmoud (2013). Also, writing compositions demands a high level of spelling proficiency in order to produce a good piece of writing.

Authors Name: Sheikha Ali Salim Al-Breiki/ a Senior English Teacher Ministry of Education

Sultanate of Oman
Arab learners of English face various difficulties when learning English spelling. A large body of research analyzes students' errors as a way of gaining insight on how students learn and how to address their learning needs. For example, Brown (2000) encouraged systematic analysis of learners' errors in order to address their needs via designing appropriate curricula. A considerable amount of research has been devoted to analyze the patterns of spelling errors (Al-Harrasi, 2012). These studies surveyed the errors in spelling and then classified them into distinct categories. To the researcher's best knowledge, no study about learners' spelling difficulties has been conducted on high school students in Oman. Therefore, this study aims to find out the most common spelling errors grade ten EFL students in Oman make

\section{Literature Review}

Spelling is defined as "the grammar of letter sequences that generates permissible combinations without regard to sound" (Peters, 1985, p. 11-12). Here, the definition suggests that spelling is not a task of translating sounds into their corresponding letters in a direct sound to letter relationship, but it is more complex than this. There are rules that govern letter combinations.

Spelling, as Moats (1984) indicated, is a multifaceted skill that depends upon several layers of knowledge; phonological awareness, morphological awareness, semantic knowledge and orthographic knowledge (cited in Santoro, Coyne \& Simmons, 2006). 
Learners' errors are significant for various instructional reasons. For example, studying learners' errors can throw some light on how learners process language and what kind of assistance they need. Wasowicz (2007) emphasized the notion that spelling errors can inform educators about the kind of linguistic knowledge individual learners possess. Also, studying learners' misspellings can inform educators about which stage of spelling development the learner is stuck at. This assessment, as indicated by Kohnen, Nickels and Castles (2009), can draw the training framework and the types of strategies needed for the learner in order to move to the next stage. Kohnen, Nickels and Castles (2009) suggested identifying learners' spelling difficulties as early as possible in order to enhance spelling abilities and to facilitate text writing.

Identifying the types of spelling problems is of central importance in the process of spelling error analysis. Classifying the spelling errors into different categories helps detect the sources of difficulties and would consequently facilitate the choice of the appropriate classroom instruction.

Studies done in the Omani context have surveyed spelling difficulties at either early grade levels such as grade four (Al-Yahyai, 2009), grade five (Al-Hassan, 2006; Al-Jabri, 2006) and grade six (Al-Harrasi,2012 ) or at a different educational system such as grade nine of general education (Al-Mezeini, 2009) or at a tertiary level (Emery, 2005; Mahmoud, 2013 ;Vaddapalli, 2012). To the researcher's best knowledge, no study about learners' spelling difficulties has been conducted on high school students in Oman. Expressed by Emery (2008), good spelling is necessary for secondary students simply because their "courses are geared towards passing written exams" (p.17). Therefore, studying grade ten students' spelling errors is of critical importance.

\section{Population and sample}

The study population comprised of all students in grade ten Basic Education in North Batinah Governorate in Oman. There were 280 male classes, 259 female classes and 5 coeducation classes in North Batinah Governorate. So, two male classes and two female classes were the random sample in this study. The total number of the participants was 90 students; 41 males and 49 females.

\section{Instruments}

An English test was given to grade ten students. It had two questions: a dictation question and a free writing task. There were seventy words in the dictation test. There were also contextualizing sentences, a sentence for each spelling word. The words were selected on the basis of familiarity and frequency. The second question was a free writing task. The students were asked to write about a given situation.

After administering the test for the students, the researcher marked the test papers, identified the misspellings and then classified them into the following categories: consonant omission, vowel omission, consonant insertion, vowel insertion, consonant substitution, vowel substitution, transposition, true word spelling error and complex spelling error.

\section{Findings and discussions}

Table 1 shows the sums and percentages of the different types of the spelling errors for grade ten students in the two test questions.

Students made a large number of spelling errors. Over ten thousand spelling errors were made by ninety students and that shows how big the spelling problem is among this grade. Table 1 presents the types of the spelling errors committed by the students. Vowel substitution was the most common type of spelling errors made by the students. Vowel omission was the second most common spelling errors. The third in the list of the spelling problems was consonant substitution while complex spelling errors came in the fourth place. Finally, consonant insertion spelling errors were the least common types of the spelling errors.

The findings in table 1 correspond with the findings of some previous studies. Emery (2005) 
found that vowel substitution was the most common type of spelling errors among all other types of errors that involved vowel letters. Also, Al-Jarf (2008) found out that substituting the vowel by another faulty vowel was the most common specific strategy used by university students in her study.

Additionally, Al-Hassan (2006) found that consonant substitution was of particular difficulty to Omani grade five male students in his study. The researcher indicated that his learners had difficulty with mirror-shaped letters, e.g. $b$ and $d$, but he did not include any percentages or means of all the error types in his analysis of the misspellings. Al-Jabri (2006) found that substitution and omission spelling errors were both the most common among his students. Yet, the researcher did not specify the types of the letters. Also, the findings of Al-Jayousi's (2011) study revealed that the spelling errors of the Arab learners of English in UAE were highly concentrated in substitution errors with as high as $50 \%$ while omission came in the second place with $33 \%$.

Substituting the correct vowel with another vowel was found to be the most common type of misspellings among grade ten students. This finding might raise the concern about phonemic awareness in the vowel sounds students possess. Vaddapalli (2012), in his study about spelling and auditory discrimination difficulties students in Oman face, concluded that "lack of phonemic awareness of English sounds is one of the main reasons of spelling problems" (p.273).

According to table 1, vowel related spelling errors seemed to be more problematic to Arab EFL learners of English than consonant related misspellings. This suggests that vowels constitute particular difficulties for Arab learners of English. Cook (1999), in his analysis of the spelling errors made by L2 users of English from different L1s, indicated that Arab learners substituted vowels and added more vowels than other L2 users and the researcher attributed this to the linguistic differences between English and Arabic. A question to be raised, were there certain vowel letters that were more problematic than others? This is a question that may constitute a possible area for future research studies.

Table 2 displays t-test results for differences between males and females in mean spelling errors in question one and question two.

The results presented in table 2 revealed that there were significant differences between male and female students with respect to two types of misspellings; vowel omission and true word errors. Male students omitted more vowels when spelling as opposed to female students. Similarly, more female students made true word errors compared to their male counterparts.

Vowel omission is a characteristic of a speller at the phonetic stage of spelling development. There were more male students at the phonetic stage than female students. This is quite alarming since phonetic spelling is an attribute of young learners' writing. Making true word errors shows that the students have good knowledge of permissible strings of letters and the constituents that are more likely to make correct words in English language. Students who make more true word errors can be said to know how a word looks right or have good orthographic knowledge; however, their semantic knowledge is poor. More exposure to the language through directed readings or extensive readings can help students develop good semantic knowledge.

Previous spelling studies based on corpus analysis did not compare the types of misspellings made by male and female students in composition writing. The difference between the different types of spelling errors with respect to gender is an area that needs further investigation.

\section{Conclusion}

Spelling instruction in Arab EFL in general and in Omani classrooms in particular should be reviewed in order to provide the appropriate spelling instruction that corresponds with students' actual spelling needs. A change to alleviate the spelling problems is necessary. This change needs to combine the efforts of all change agents in education namely curriculum designers, supervisors, trainers and teachers. 
Proc. of The Second Intl. Conf. On Advances In Economics, Social Science and Human Behaviour Study - ESSHBS 2015 Copyright ( Institute of Research Engineers and Doctors, USA .All rights reserved. ISBN: 978-1-63248-076-7 doi: 10.15224/ 978-1-63248-076-7-85

\section{Recommendations}

In light of the findings of the present study, the following recommendations are made.

1. It crucial to evaluate students' spelling proficiency particularly at the beginning of grade ten in order to measure students' actual achievements in spelling through the nine years of learning English. Subsequently, stakeholders at the curriculum department in the Ministry of Education are well informed about students' actual needs and thus can design the most appropriate intervention programs.

2. Teachers need to be well trained to deal with students' spelling difficulties. Therefore, curriculum developers in coordination with training and supervision departments can survey teachers' training needs with respect to teaching and learning spelling. Then, in-service training needs that can correspond with students' actual needs can be designed and implemented.

3. English language syllabus can include more effective spelling learning strategies for students to employ when learning spelling.

4. Further studies on spelling problems might consider investigating the misspellings of different grade levels.

5. Comparisons between the spelling performance of different grade levels, e.g. between grade five and grade ten, are recommended in order to examine whether students make different types of spelling errors as they progress through the years of learning English or not.

6. Testing the effectiveness of a teaching approach or a teaching/learning strategy for spelling is recommended in order to measure their effect on improving students' spelling proficiency.

\section{References}

Al-Harrasi, K. (2012). The most common spelling errors among Omani learners. Arab World English Journal, 3(2), 96-116.

Al-Hassan, S. (2006). An alternative approach to teaching spelling in grade 5. In S. Borg (Ed.), Classroom Research in ELT in Oman (pp.81-87). Sultanate of Oman: Ministry of Education.

Al-Jabri, F. (2006). Common English spelling difficulties of Omani learners. In S. Borg (Ed.), Classroom Research in ELT in Oman (pp.88-93). Sultanate of Oman: Ministry of Education.
Al-Jarf, R. (2008). Listening Spelling Strategies in EFL Arab College Students.

Al-Jayousi, M.T. (2011). Spelling errors of Arab students: Types, causes and teachers' responses. Master Thesis. American University of Sharjah.

Al-Mezeini, H. (2009). Does teaching spelling rules make a difference?. In S. Borg (Ed.), Understanding English Language Teaching and Learning in Oman (pp. 124-131). Sultanate of Oman: Ministry of Education.

Al-Yahyai, S. (2009). Spelling Difficulties in Grade 4. In S. Borg (Ed.),Understanding English Language Teaching and Learning in Oman (pp.132-139) Sultanate of Oman: Ministry of Education.

Brown, H. D. (2000). Principles of language learning and teaching $\left(4^{\text {th }}\right.$ edition). White Plains, NY: Pearson Education.

Cook, V. (1999). Teaching spelling. Retrieved from http://homepage.ntlworld.com/vivian.c/Writings/P apers/TeachingSpelling.htm

Emery, H. (2005). An investigation into the nature and causes of reading and spelling errors made by Arab ESL learners. (PhD thesis). The University of Wales, Cardiff.

Emery, H. (2008). Eyes and ears. English Teaching Professional, 55, 17-19.

Kohnen, S., Nickles, L. \& Castles, A. (2009). Assessing spelling skills and strategies: A critique of available resources, Australian Journal of Learning Difficulties, 14(1), 113-150. doi: 10.1080/19404150902783450

Mahmoud, A. (2013). Spelling errors of Arab learners of EFL: A two-way analysis. TESOL Arabia Perspectives, 20(1), 6-12.

Peters, M. L. (1985). Spelling caught or taught: A new Look. London: Routledge \& Kegan Paul plc.

Santoro, L., Coyne, M. \& Simmons, D. (2006). The reading-spelling connection: Developing and evaluating a beginning spelling intervention for children at risk of reading disability. Learning Disabilities Practice, 21(2), 122-133.

Vaddapalli, M. (2012). Spelling and auditory discrimination difficulties of students in Oman: An analysis. Language in India, 12(1), 261-276.

Wasowicz, J. (2007). What do spelling errors tell us about language knowledge? Retrieved from: http://www.learningbydesign.com/uploads/ What_Do_Spelling_Errors_Tell_Us_ Language_Knowledge.pdf 
Proc. of The Second Intl. Conf. On Advances In Economics, Social Science and Human Behaviour Study - ESSHBS 2015

Table 1

\begin{tabular}{lcr} 
The Types of the Spelling Errors & Sum & $*$ Percentage \\
\hline Vowel Substitution & 2470 & $24.58 \%$ \\
Vowel Omission & 2131 & $21.29 \%$ \\
Consonant Substitution & 1698 & $16.90 \%$ \\
Complex Spelling Error & 1246 & $12.40 \%$ \\
Consonant Omission & 1039 & $10.34 \%$ \\
True Word Error & 535 & $5.32 \%$ \\
Vowel Insertion & 524 & $5.21 \%$ \\
Transposition & 271 & $2.70 \%$ \\
Consonant Insertion & 136 & $1.35 \%$ \\
Total & 10,050 & \\
\hline
\end{tabular}

Sums and Percentages of the Different Types of the Spelling Errors for all Students in Test Questions One and Two

*out of the total number of the errors

Table 2

\begin{tabular}{cccccc}
\hline $\begin{array}{c}\text { Types of the } \\
\text { Spelling Errors }\end{array}$ & Gender & & & & $\begin{array}{c}\text { Sig.(2- } \\
\text { tailed) }\end{array}$ \\
\hline Consonant Omission & Male & 12.60 & 4.91 & 1.77 & .08 \\
& Female & 10.88 & 4.33 & & \\
Vowel Omission & Male & 27.27 & 10.65 & 3.23 & $.00 * *$ \\
& Female & 20.67 & 8.71 & & \\
Consonant Insertion & Male & 2.18 & 1.39 & .11 & .92 \\
& Female & 2.14 & 1.29 & & \\
Vowel Insertion & Male & 5.29 & 3.53 & 1.49 & .14 \\
& Female & 6.53 & 4.20 & & \\
Consonant Substitution & Male & 20.80 & 9.70 & 1.91 & .06 \\
& Female & 17.24 & 8.00 & & \\
Vowel Substitution & Male & 27.22 & 10.57 & .18 & .86 \\
& Female & 27.63 & 11.58 & & \\
Transposition & Male & 3.61 & 2.64 & .46 & .65 \\
& Female & 4.05 & 4.54 & & \\
True Word Error & Male & 5.17 & 2.60 & 2.21 & $.03 * *$ \\
& Female & 6.59 & 3.36 & & \\
Complex Spelling & Male & 16.33 & 10.73 & 1.59 & .12 \\
Error & Female & 12.89 & 9.31 & & \\
\hline
\end{tabular}

T-test Results for Differences between Males and Females in Mean Spelling Errors in Questions One and Two of the Test

*The average of misspellings for each student

** The mean difference is significant at .05 level 